\title{
Achados microbiológicos, moleculares e histopatológicos em pequenos ruminantes experimentalmente infectados com Actinobacillus seminis ${ }^{1}$
}

\begin{abstract}
Fabrine A. Santos², Felício Garino Júnior², Pomy C.P. Kim³ , Jean L. Araújo², Sergio S. Azevedo $^{2}$, Rinaldo A. Mota ${ }^{3}$, Antônio F.M. Dantas ${ }^{2}$ e Clebert J. Alves ${ }^{2 *}$

ABSTRACT.- Santos F.A., Garino Júnior F., Kim P.C.P., Araújo J.L., Azevedo S.S., Mota R.A., Dantas A.F.M. \& Alves C.J. 2017. [Microbiological, molecular and histopathological findings in small ruminants experimentally infected with Actinobacillus seminis.] Achados microbiológicos, moleculares e histopatológicos em pequenos ruminantes experimentalmente infectados com Actinobacilus seminis. Pesquisa Veterinária Brasileira 37(7):686-690. Programa de Pós-Graduação em Medicina Veterinária, Universidade Federal de Campina Grande, Av. Universitária s/n, Santa Cecília, Patos, PB 58700-970, Brazil. E-mail: clebertja@uol.com.br

The aim of this study was to evaluate, in sheep, the pathogenicity of an Actinobacillus seminis strain isolated from a goat in Brazil. Samples of semen, puncture and fragments of epididymis, deferent duct, testicles and seminal vesicles from two goats (animals 1 and 2) and two sheep (animals 3 and 4) were used, and histopathological, microbiological culture and molecular diagnoses were performed. The inoculum was prepared with saline solution at $10^{-2}$ dilution corresponding to $1.0 \mathrm{McFarland}$ standard, with $A$. seminis colonies previously cultured and administered on $2 \mathrm{~mL}$ volume by intra-preputial (animals 1 and 3 ) and epididymis tail (animals 2 and 4 ) routes. At clinical evaluation it were found unilateral swelling of firm consistency after 30 days in epididymis and testicle from animal 4 that continued until the day of euthanasia, as well as animal 1 shown discrete unilateral swelling of testicles. Gross and microscopic lesions in animals 3 and 4 were compatibles with that caused by A. seminis infection. A. seminis was isolated from material of puncture and semen of one sheep (animal 4). It is concluded that the experimental infection model using goats and sheep has proved the pathogenicity of the A. seminis strain isolated from a goat in the Brazilian semiarid and reproduced in a sheep, which confirm the prediletion of the agent for epididymis, with clinical signs, histopathological findings, bacterial isolation and positive molecular diagnosis.
\end{abstract}

INDEX TERMS: Epididymitis, Actinobacillus seminis, experimental infection.

RESUMO.- O objetivo deste trabalho foi avaliar a patogenicidade, em ovinos, de uma cepa de Actinobacillus seminis isolada de caprino no Brasil. Foram utilizadas amostras de sêmen, punção e fragmentos de epidídimo, ducto deferente, testículos e glândulas seminíferas de dois caprinos (ani-

\footnotetext{
${ }^{1}$ Recebido em 14 de abril de 2016.

Aceito para publicação em 17 de dezembro de 2016.

${ }^{2}$ Unidade Acadêmica de Medicina Veterinária (UAMV), Universidade Federal de Campina Grande (UFCG), Av. Universitária s/n, Cx. Postal 61, Santa Cecília, Patos, PB 58700-970, Brasil. *Autor para correspondência: clebertja@uol.com.br

${ }^{3}$ Departamento de Medicina Veterinária, Universidade Federal Rural de Pernambuco (UFRPE), Recife, PE 52171-900, Brasil.
}

mais 1 e 2) e dois ovinos (animais 3 e 4), e foram realizados exame histopatológico, cultivo microbiológico e diagnóstico molecular. 0 inóculo foi preparado com solução salina na diluição de $10^{-2}$ correspondendo ao padrão 1,0 da escala de McFarland, com colônias previamente cultivadas de $A$. seminis e administrado no volume de $2 \mathrm{~mL}$ pelas vias intra-prepucial (animais 1 e 3) e na cauda do epidídimo (animais 2 e 4). Na avaliação clínica observou-se aumento unilateral de consistência firme após 30 dias no epidídimo e testículo do animal 4 que continuou até o dia da eutanásia, bem como o animal 1 apresentou discreto aumento unilateral dos testículos. As lesões macroscópicas e microscópicas observadas nos animais 3 e 4 foram compatíveis com 
aquelas causadas pela infecção por A. seminis. A. seminis foi isolado de material de punção e sêmen de um ovino (animal 4). Conclui-se que o modelo de infecção experimental utilizando caprinos e ovinos comprovou a patogenicidade da amostra de $A$. seminis, isolada de um caprino no semiárido brasileiro e reproduzida em um ovino, comprovando a predileção do agente pelo epidídimo, com quadro clinico, achados histopatológicos, isolamento bacteriano e diagnóstico molecular positivo.

TERMOS DE INDEXAÇÃO: Epididimite, Actinobacillus seminis, infecção experimental.

\section{INTRODUÇÃO}

A epididimite ovina tem sido relatada como uma das principais causas de prejuízos econômicos, pois interfere na fertilidade dos machos infectados, de maneira que tais perdas não são percebidas facilmente em criações extensivas devido à falta de informação dos produtores sobre essa doença (Gomes 1991). Um dos principais agentes causais é Actinobacillus seminis, uma bactéria Gram-negativa da família Pasteurellaceae, cuja infecção se estabelece quando os machos ainda jovens alcançam a maturidade sexual, mas também diagnosticada em animais adultos. Clinicamente, a infecção por A seminis caracteriza-se por alterações inflamatórias crônicas que envolvem o epidídimo e o testículo (Bezerra et al. 2012). A patogenia é incerta, mas sugere-se que $A$. seminis seja um micro-organismo oportunista presente na cavidade prepucial capaz de colonizar as partes profundas do trato genital (Dibarrat et al. 2006). Um dos possíveis fatores predisponentes pode estar associado ao estresse induzido por mudanças hormonais durante a maturação sexual ou por deficiências nutricionais, ocasionando o desenvolvimento de orquite e epididimite, principalmente em carneiros jovens (Hajtós et al. 1987).

0 primeiro isolamento de $A$. seminis foi relatado por Baynes \& Simmons (1960), na Austrália, em sêmen de ovinos com epididimite. A partir daí, a bactéria foi isolada de ovinos em diversas ocasiões em vários países: Estados Unidos da América (Livingston \& Hardy 1964), África do Sul (Worthington \& Bosman 1968), Nova Zelândia (Gumbrell \& Smith 1974), Hungria (Hajtós et al. 1987), Argentina (Robles et al. 1990), Reino Unido (Heath et al. 1991) e Espanha (Puente-Redondo et al. 2000). No Brasil, existem apenas cinco relatos de isolamento de $A$. seminis em ovinos (Schreiner et al. 1992, Gomes et al. 2001, Gregory et al. 2009, Bezerra et al. 2012) e um em caprinos (Santos et al. 2014).

Tendo em vista que recentemente foi efetuado o primeiro isolamento de $A$. seminis em caprinos no Brasil (Santos et al. 2014), o objetivo do presente trabalho foi avaliar, em ovinos, a patogenicidade da cepa (denominada SAAS01) isolada previamente em caprinos.

\section{MATERIAL E MÉTODOS}

O projeto foi aprovado pelo Comitê de Ética em Pesquisa (CEP) da Universidade Federal de Campina Grande através do protocolo CEP 249/2015.

Foram selecionados quatro animais, sendo dois caprinos (animais 1 e 2) e dois ovinos (animais 3 e 4), machos com idade de reprodução e clinicamente sadios. Os animais foram previamente testados para Brucella ovis pelo teste de imunodifusão em gel de ágar (IDGA) com kits comerciais produzidos pelo Instituto de Tecnologia do Paraná (TECPAR, Curitiba, Brasil); a técnica foi realizada de acordo com as instruções do fabricante, utilizando-se antígeno de lipopolissacarídeos e proteínas de B. ovis, amostra Reo 198 onde todos os animais foram negativos na pesquisa de anticorpos anti-B. ovis.

O experimento foi realizado no Hospital Veterinário da Universidade Federal de Campina Grande, em Patos, PB, Brasil. Os animais inicialmente foram adaptados em baias por período de 15 dias e alimentados com feno de capim tifton e farelo de milho e trigo. Após esse período foram inoculados com Actinobacillus seminis (amostra SAAS01) (Santos et al. 2014). O inóculo foi preparado com solução salina na diluição de $10^{-2}$ correspondendo ao padrão 1,0 da escala de McFarland, com colônias previamente cultivadas de $A$. seminis e administrado no volume de $2 \mathrm{~mL}$ por via intra-prepucial em dois animais, sendo um caprino e um ovino, e os dois animais restantes foram inoculados na cauda do epidídimo. Os animais foram analisados clinicamente por período de 12 semanas, e na ocasião foram feitas punções na cauda do epidídimo e coleta de sêmen por eletro-ejaculação a cada três semanas, totalizando quatro coletas. Após o tempo proposto, os animais foram eutanasiados após a sedação com xilazina (Copazine-Schering-Plough Coopers, Brasil) na dose de $0,5 \mathrm{mg} / \mathrm{kg}$ de peso vivo e anestesia geral com tiopental sódico 2,5\% (Cristália Produtos Químicos Farmacêuticos Ltda) na dose de $10 \mathrm{mg} / \mathrm{kg}$ peso vivo, seguido por eletrocussão e submetidos à necropsia para coleta de fragmentos do corpo e cauda do epidídimo, ducto deferente, testículo e glândulas seminais. Essas amostras foram submetidas aos diagnósticos histopatológico, microbiológico e molecular. No momento da coleta do sêmen, foi utilizado eletro ejaculador específico para pequenos ruminantes com ondas e amplitudes padronizadas, gel lubrificante, sob orientação de especialistas em reprodução animal.

As amostras de tecidos e de sêmen foram semeadas nos meios ágar sangue e ágar Brucella enriquecidos com sangue desfibrinado de carneiro na concentração de $5 \%$ do volume total. Todas as amostras foram incubadas em atmosfera contendo $10 \%$ de $\mathrm{CO}_{2}$ bem como em aerobiose por período de cinco dias. As bactérias isoladas foram submetidas às provas bioquímicas de catalase, oxidase, nitrato, esculina, motilidade, maltose, xilose, galactose, lactose, manose e trealose, conforme Krieg \& Holt (1984). Para o diagnóstico histopatológico, as amostras foram fixadas em formalina a $10 \%$, desidratadas, diafanizadas e incluídas em parafina. Os blocos foram cortados em micrótomo de $5 \mu \mathrm{m}$ e as lâminas coradas pela técnica de Hematoxilina-Eosina (HE).

Para o diagnóstico molecular por reação em cadeia pela polimerase (PCR), as amostras de sêmen, punção, fragmentos dos órgãos e cultivo foram submetidas à extração de DNA utilizando-se Kit comercial "Qiagen DNA EasyBloodandTissues Kit" (Qiagen $^{\circledR}$, Austin, USA), seguindo o protocolo do fabricante. Os primers utilizados foram SRJAS1 (CTTATCTTTCTTAAGCCCTGAC) e SRJAS2 (AAGAAAAAGACGAAGAGACATT) segundo Appuhamy et al. (1998b), que amplificam fragmento com 436pb da região $16 \mathrm{~S}$ do rRNA. As reações de amplificação foram realizadas em volume final de $12,5 \mu \mathrm{L}$ contendo $2,5 \mu \mathrm{L}$ de DNA genômico; $0,5 \mu \mathrm{L}$ de cada primer a $30 \mu \mathrm{M} ; 2,5 \mu \mathrm{L}$ de água ultrapura (Mili- $\mathrm{Q}^{\circledR}$, Darmstadt, Alemanha) e 6,25 $\mu \mathrm{L}$ de Top Taq Master Mix (Qiagen ${ }^{\circledR}$, Austin, EUA), de acordo com o protocolo do fornecedor. 0 perfil térmico das etapas de reações foi feito em termociclador XP Thermal Cycler (Bioxer Technology Co Ltda, Qingdao, China), consistindo de desnaturação do DNA inicial a $94^{\circ} \mathrm{C}(1 \mathrm{~min})$ e seguida de 35 ciclos a $94^{\circ} \mathrm{C}$ por 30 segundos para a desnaturação, $55^{\circ} \mathrm{C}$ por 30 segundos para o anelamento, $72^{\circ} \mathrm{C}$ por 6 minutos para a extensão e extensão 
Quadro 1. Resultados da inoculação experimental de amostra de Actinobacillus seminis (amostra SAAS01) isolada de caprino

\begin{tabular}{ccccccc}
\hline $\begin{array}{c}\text { Identificação } \\
\text { do animal }\end{array}$ & Espécie & $\begin{array}{c}\text { Via de } \\
\text { inoculação }\end{array}$ & $\begin{array}{c}\text { Sinais } \\
\text { clínicos }\end{array}$ & $\begin{array}{c}\text { Cultivo e } \\
\text { isolamento }\end{array}$ & $\begin{array}{c}\text { Achados } \\
\text { histopatológicos }\end{array}$ & $\begin{array}{c}\text { PCR } \\
1\end{array}$ \\
\hline Caprino & Intra-prepucial & + & - & - & - \\
3 & Caprino & Cauda do epidídimo & - & - & - & - \\
4 & Ovino & Intra-prepucial & - & - & + & - \\
& Ovino & Cauda do epidídimo & + & + & + & +
\end{tabular}

final de 1 minuto a $72^{\circ} \mathrm{C}$, de acordo com Appuhamy et al. (1998a). Os produtos amplificados foram analisados por eletroforese em gel de agarose a 1,2\%. As bandas de DNA foram visualizadas sob luz UV.

\section{RESULTADOS}

No Quadro 1 estão apresentados os resultados de acordo com a espécie animal e via de inoculação. Na avaliação clínica pode-se observar aumento unilateral de consistência firme após 30 dias no epidídimo e testículo do animal 4 que continuou até o dia da eutanásia. 0 animal 1 também apresentou discreto aumento unilateral dos testículos aproximadamente no mesmo período. Já o animal 3 apresentou apenas achados histopatológicos e o animal 2 não apresentou alterações significativas.

Foi possível o isolamento de colônias pequenas ( 1 a 2 $\mathrm{mm}$ ), lisas, brilhantes e sem pigmento a partir de material de punção e sêmen de um ovino (animal 4) colhido na 3 a e $4^{\text {a }}$ coleta. Na coloração de Gram, foram identificadas bactérias com morfologia de bastonetes Gram negativas. 0 isolado foi catalase, oxidase, nitrato e esculina positivas e motilidade negativa, produção de ácido em maltose e xilose, sem produção de ácido em galactose, lactose, manose e trealose. As características morfotintoriais e bioquímicas permitiram identificá-lo como sendo Actinobcillus seminis. Não houve crescimento bacteriano sugestivo de $A$. seminis em materiais dos animais 1,2 e 3 .

$\mathrm{Na}$ necropsia, foram observados aumento de volume unilateral da cauda, cabeça e corpo do epidídimo e pequeno foco de exsudato pastoso de cor branco acinzentado no animal 4. Já no animal 3, observou-se fibrose, atrofia e mineralização testicular e epididimal bilateral.

Ao exame histopatológico foi observada, no animal 3, área focal de necrose na glândula vesical contendo restos de espermatozoides e material eosinofílico circundado por intensa reação inflamatória granulomatosa (Fig.1) constituída por macrófagos epitelioides e células gigantes multinucleadas (Fig.2), além de alguns linfócitos, plasmócitos e raros neutrófilos, limitada por cápsula de tecido conjuntivo fibroso. Algumas células gigantes apresentavam-se fagocitando o material eosinofílico e restos de espermatozoides. No animal 4 foi observada presença de infiltrado inflamatório multifocal na glândula vesical com número discreto de neutrófilos, muitos degenerados, na luz das glândulas. Em algumas áreas esse infiltrado inflamatório foi observado na lâmina própria e entre as glândulas (intersticial), além de áreas de necrose epitelial. No corpo do epidídimo foi observada grande quantidade de neutrófilos, alguns degenerados, na luz do ducto epididimário. Em algumas áreas havia material finamente granular e basofílico carac-

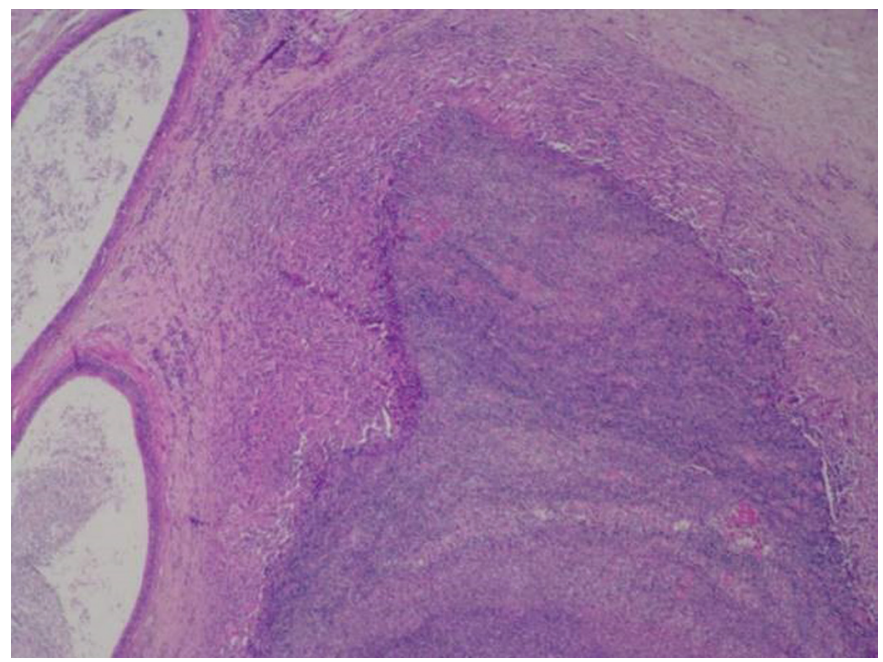

Fig.1. Glândula seminal do animal 3 apresentando área de necrose central circundada por inflamação granulomatosa. HE, obj.20x.

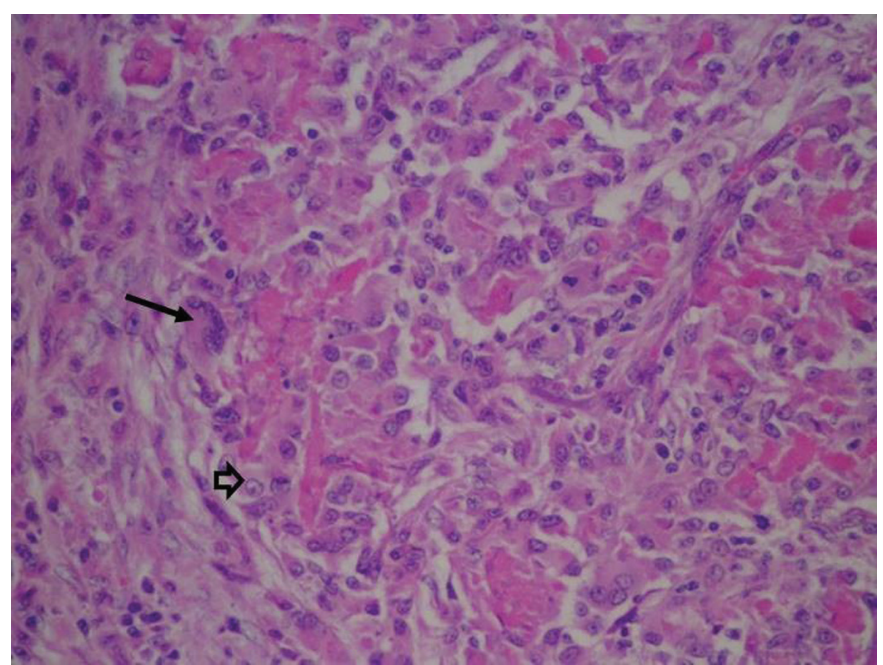

Fig.2. Glândula seminal do animal 3 apresentando material eosinofílico circundado por infiltrado inflamatório constituído por macrófagos epitelioides (cabeças de setas) e células gigantes multinucleadas (seta). HE, obj.40x.

terístico de agregados bacterianos e infiltrado inflamatório neutrofílico com necrose focal do epitélio glandular (Fig.3). No testículo, observaram-se áreas multifocais e discretas de necrose com raras células inflamatórias polimorfonucleares.

Foi amplificado DNA de A. seminis a partir de sêmen do animal 4. 0 produto amplificado da amostra revelou fragmento do tamanho indicado ao descrito para os primers utilizados para A. seminis (Fig.4). 


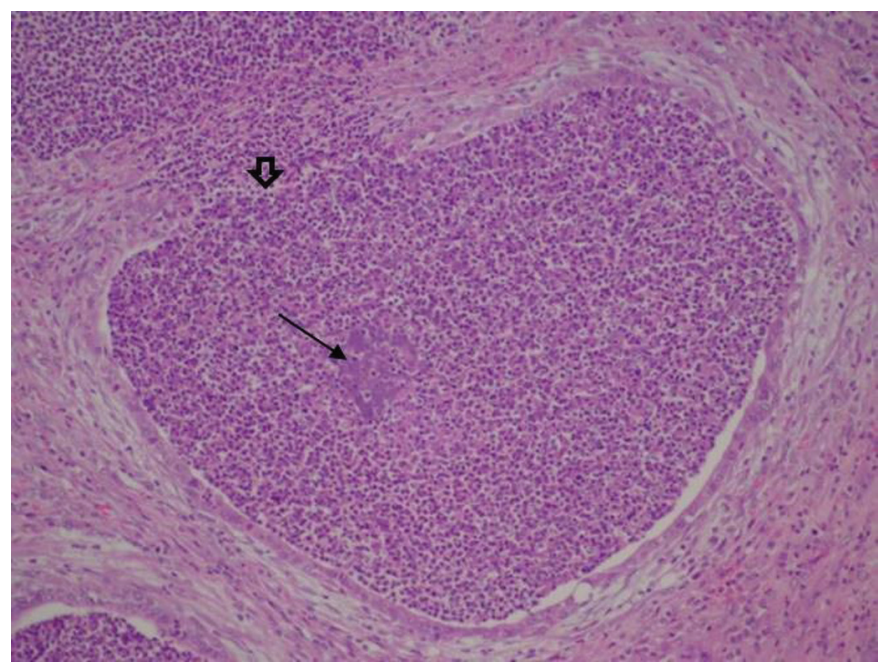

Fig.3. Corpo do epidídimo do animal 4 contendo infiltrados de neutófilos, alguns degenerados e agregados bacterianos (seta) distendendo a luz do ducto com necrose epitelial focal (cabeça de seta) e neutrófilos intersticiais. HE, obj.20x.

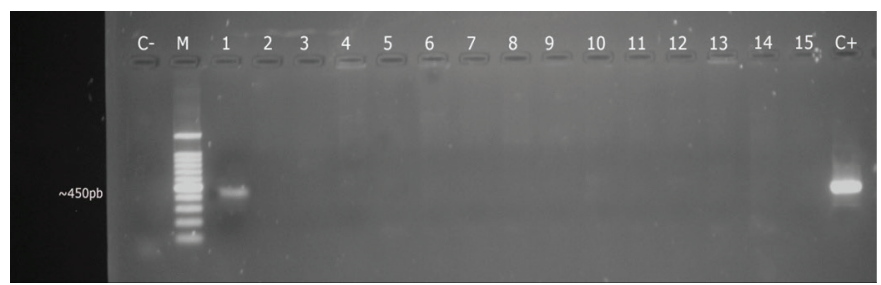

Fig.4. Análise de PCR para Actinobacillus seminis. C- = controle negativo; $\mathrm{M}=$ marcador de tamanho molecular de $100 \mathrm{pb} ; 1=$ sêmen do animal 4; 2 = fragmento de testículo do animal 3; 3 = fragmento de testículo do animal $2 ; 4$ = fragmento de testículo do animal $1 ; 5=$ fragmento de epidídimo do animal $4 ; 6=$ fragmento de epidídimo do animal 3; 7 = fragmento de epidídimo do animal $2 ; 8$ = fragmento de epidídimo do animal $1 ; 9$ = fragmento de glândula seminal do animal 4; 10 = fragmento de glândula seminal do animal 3; 11 = fragmento de glândula seminal do animal 2; 12 = fragmento de glândula seminal do animal 1; 13 = colônias de cultivo de material de punção testicular do animal 4; 14= fragmento da glândula seminal do animal 1; 15 = fragmento da glândula seminal do animal 2; C+ $=$ controle positivo.

\section{DISCUSSÃO}

Clinicamente, a infecção por Actinobacillus seminis caracteriza-se por alterações inflamatórias crônicas que envolvem o epidídimo e o testículo (Bezerra et al. 2012). Estas alterações foram devidamente comprovadas quando da avaliação clínica dos quatro animais reprodutores das espécies caprina e ovina, e o animal 4 apresentava quadro clínico de orquite e epididimite unilateral com consistência firme, achados confirmados também por Al-Katib \& Denis (2007) e Moustacas et al. (2014) em trabalho de infecção experimental, que confirma a predileção do A. seminis pela cauda do epidídimo. Deve ser destacado que as alterações clinicas estão associadas à baixa concentração, baixa motilidade e a não viabilidade espermática, além da presença de neutrófilos no sêmen, que comprometem a taxa de fertilidade dos reprodutores, e em regiões sem histórico de diagnóstico da infecção os prejuízos econômicos podem ser ainda maiores devido à dificuldade de identificação dos sintomas.

Os achados relacionados às lesões macroscópicas observadas quando da necropsia do animal 4 vem ao encontro aos relatos descritos por outros autores, que descreveram lesões caracterizadas por aumento de volume da cauda do epidídimo, de um ou de ambos os testículos, mas a cabeça e o corpo também podem estar afetados, espessamento da túnica albugínea, epididimite, orquite, atrofia e diminuição na consistência testicular, além de abscessos na cauda do epidídimo (Al-Katib \& Denis 2007, Moustacas et al. 2014), no testículo e no saco escrotal, exsudato purulento, pastoso ou granular, branco acinzentado, ou material calcificado pode ser encontrado unilateral ou bilateralmente (West 2004, Foster \& Lads 2007, Moustacas et al. 2014). Ainda pode ser encontrado aumento dos linfonodos inguinais e ilíacos internos. 0 quadro de lesões deve ser considerado no diagnóstico das epididimites infecciosas agudas, embora a sua etiologia só possa ser definida por meio do exame bacteriológico ou técnicas moleculares, pois outras bactérias podem causar lesões semelhantes (Bezerra et al. 2012). No animal 3, embora não tenha sido possível detectar a presença de isolados bacterianos, lesões como atrofia, fibrose e mineralização testicular e epididimal bilaterais são compatíveis com o quadro crônico da enfermidade, o que dificulta o isolamento bacteriano.

Na epididimite subaguda a crônica, as lesões histológicas causadas pelo $A$. seminis geralmente consistem de edema e fibrose intersticial do epidídimo, oclusão dos ductos epididimários com ausência de espermatozoides, reação inflamatória predominantemente linfoplasmocitária intersticial multifocal no testículo, mineralização de alguns túbulos seminíferos, necrose e inflamação piogranulomatosa no epidídimo e testículo, redução ou ausência de espermatozoides nos túbulos seminíferos, áreas de vacuolização do epitélio com pouca evidência de espermatogênese, além de atrofia tubular com retenção espermática e formação de granulomas (Baynes \& Simmons 1960, Tonder 1973, Puente-Redondo et al. 2000, Gomes et al. 2001, West 2004). Na infecção aguda, as lesões descritas por West (2004) correspondem a necrose, descamação do epitélio e alterações císticas dos túbulos da parte afetada do epidídimo, infiltração por neutrófilos, e alguns macrófagos e linfócitos, e degeneração e necrose de neutrófilos e espermatozoides. Os achados microscópicos observados nos animais 3 e 4 estão semelhantes com os citados na literatura.

A ausência de crescimento bacteriano sugestivo para A. seminis em materiais dos animais 1,2 e 3 , a despeito que no animal 3 tenha sido possível verificar lesões como atrofia, fibrose e mineralização testicular e epidídimal bilateral compatíveis com quadro crônico da enfermidade e no animal 1 a ausência de isolamento bacteriano, achados histológicos e amplificação de material genético em contra posição a presença de sinais clínicos, vem reforçar os achados de Moustacas et al. (2014) ao relatarem que houve baixa frequência de isolamento bacteriano a partir do sitio de inoculação e sugere que a cronicidade da infecção na cauda do epidídimo pode interferir na recuperação da bactéria.

Analisando-se os indicadores de produção, há relatos 
que revelam deficiências sanitárias em relação à criação de pequenos ruminantes na região semiárida do Nordeste do Brasil (Pinheiro et al. 2000), demonstrando a necessidade de minimização dos prejuízos provocados pelas perdas reprodutivas. Em particular, destacam-se as características da infecção por $A$. seminis, cujos efeitos não são perceptíveis nem mensuráveis (Gomes 1991), especialmente em criações extensivas ou por produtores não alertados para a importância econômica da doença (Bezerra et al. 2012).

0 isolamento de $A$. seminis em um animal experimentalmente inoculado com uma cepa oriunda do primeiro isolamento em caprinos no Brasil (Santos et al. 2014), e confirmação por diagnóstico molecular se reveste de importância em função do que representa a atividade da caprinovincultura no contexto da cadeia produtiva e seus impactos econômicos para a região semiárida do Nordeste do Brasil, visto que a infecção foi reproduzida em ovino com cepa isolada de caprino. Diante disso, o A. seminis deve ser considerado como diagnóstico diferencial em casos de epididimite em pequenos ruminantes, especialmente na região Nordeste do Brasil, onde a criação consorciada de caprinos e ovinos é uma prática amplamente adotada e o agente já foi isolado em ovinos (Bezerra et al. 2012) e em caprinos (Santos et al. 2014), podendo ser esse modelo de criação decisivo na contaminação cruzada entre ovinos e caprinos.

\section{CONCLUSÃO}

Conclui-se que o modelo de infecção experimental utilizando caprinos e ovinos comprovou a patogenicidade da amostra de Actinobacillus seminis, isolada de um caprino no semiárido brasileiro e reproduzida em um ovino, comprovando a predileção do agente pelo epidídimo, com quadro clinico, achados histopatológicos, isolamento bacteriano e diagnóstico molecular positivo.

Agradecimentos.- À Coordenação de Aperfeiçoamento de Pessoal de Nível Superior (CAPES), pela concessão da bolsa de Pós-Graduação.

\section{REFERÊNCIAS}

Al-Katib W.A. \& Dennis S.M. 2007. Epididymal and testicular lesions in rams following experimental infection with Actinobacillus seminis. N.Z. Vet. J. 55(3):125-129.

Appuhamy S., Coote J.G., Low J.C. \& Parton R. 1998a. PCR methods for rapid identification and characterization of Actinobacillus seminis strains. J. Clin. Microbiol. 36:814-817.

Appuhamy S., Low J.C., Parton R. \& Coote J.G. 1998b. Specifc PCR primers from the Actinobacillus seminis. J. Appl. Microbiol., 185:941-948.

Baynes I.D. \& Simmons G.C. 1960. Ovine epididymitis caused by Actinobacillus seminis $n$. sp. Aust. Vet. J. 36:454-459.

Bezerra M.J.G., Santos A.S., Cruz J.A.L.O., Kung E.S., Sá S.G., Jabour F.F., Brito M.F. \& Mota R.A. 2012. Epididimite ovina por Actinobacillus seminis no Estado de Pernambuco. Pesq. Vet. Bras. 32(5):369-373.

Dibarrat J.A., Aparicio E.D., Reynoso B.A., Aparicio B.D., Gutiérrez V.R.T. \& Pérez J.T. 2006. Inducción experimental de epididimitis en ovinos por inoculación intrauretral com Actinobacillus seminis: estudio bacteriológico, serológico e histopatológico. Téc. Pecu. Méx. 44:257-267.

Foster R.A. \& Lads P.W. 2007. Male genital system, p.590-591. In: Jubb K.V.F., Kennedy P.C. \& Palmer N. (Eds), Phatology of Domestic Animals. 5th ed. Saunders Elsevier, Toronto.

Gomes M.J.P. 1991. Isolamento e identificação de Chlamydia psittacide reprodutores bovinos com adenite vesicular, no Estado do Rio Grande do Sul. Dissertação de Mestrado em Microbiologia Veterinária, Universidade Federal Rural do Rio de Janeiro, Seropédica. RJ. 95p.

Gomes M.J.P., Driemeier D., Bonetti A.L., Eidt M. \& Azambuja D.R. 2001. Epididimite ovina: isolamento de Actinobacillus seminis, no Rio Grande do Sul, Brasil. Arq. Fac. Vet. UFRGS 29:55-58.

Gregory L., Rizzo H.H., Meira Junior E.B.S., Lins G.J.V., Lins G.P.V. \& Pinheiro E.S. 2009. Relato do primeiro caso de orquite e epididimite unilateral ovina causada por Actinobacillus seminis no estado de São Paulo, Brasil. Revta Bras. Reprod. Anim. 33(2):105-107.

Gumbrell R.C. \& Smith J.M.B. 1974. Deoxyribonucleic acid base composition of ovine Actinobacilli. J. Gen. Microbiol. 84:399-402.

Hajtós I., Fodor L., Glávits R. \& Varga J. 1987. Isolation and characterization of Actinobacillus seminis strains from ovine semen samples and epididymitis. Zentralbl. Veterinärmed. B 34:138-147.

Heath P.J., Davies I.H., Morgan J.H. \& Aitken I.A. 1991. Isolation of Actinobacillus seminis from rams in United Kingdom. Vet. Rec. 129:304-307.

Krieg N.R. \& Holt J.G. 1984. Bergey's Manual of Systematic Bacteriology. Williams and Wilkins, Baltimore, p.660-663.

Livingston C.W. \& Hardy W.T. 1964. Isolation of Actinobacillus seminis from ovine epididymitis. Am. J. Vet. Res. 25:660-663.

Moustacas V.S., Silva T.M.A., Costa L.F., Carvalho Junior C.A., Santos R.L. \& Paixão T.A. 2014. Clinical and pathological changes in rams experimentally Infected with Actinobacillus seminis and Histophilus somni. Sci. World J. 2014:1-10.

Pinheiro R.R., Gouveia A.M.G., Alves F.S.F. \& Haddad J.P.A. 2000. Aspectos epidemiológicos da caprinocultura cearense. Arq. Bras. Med. Vet. Zootec. 52(5):534-543.

Puente-Redondo D.A., García del Blanco N., Pérez-Martínez C., González-Rodríguez M.C., Rodríguez-Ferri E.F. \& Gutiérrez-Martín C.B. 2000. Isolation of Actinobacillus seminis from the genital tract of rams in Spain. J. Comp. Pathol. 122:217-222.

Robles C.A., Urcullu J.A., Uzal F.A. \& Merio R. 1990. Primer diagnostico em Patagonia de orchideoepididimitis em carneros por bacilos pleomorficos gram negativos. Vet. Argent. 7:453-455.

Santos F.A., Azevedo E.O., Azevedo S.S., Garino Junior F., Mota R.A., Kim P.C.P., Gomes A.L.V. \& Alves C.J. 2014. Isolation of Actinobacillus seminis from a goat with clinical epididymo-orchitis in Brazil. Braz. J. Microbiol. 45(1):205-209.

Schreiner E., Gomes M.J.P., Cardoso M.I., Fernandes J.C.T., Hope L.P., Laitano J.L.L. \& Fernandes R.E. 1992. Epididimite ovina: isolamento de Actinobacillus seminis em Central de Inseminação Artificial no Rio Grande do Sul. XI Congresso Estadual de Medicina Veterinária, Gramado, RS, p.96. (Resumo)

Tonder E.M.V. 1973. Infection of rams with Actinobacillus seminis. J. South African Vet. Med. Assoc. 44:235-240.

West D.M. 2004. Gram-negative pleomorphic infections: Actinobacillus seminis, Histophilus ovisand Haemophilus sommi, p.1655-1660. In: Coetzer J.A.W. \& Tustin R.C. (Eds), Infectious Diseases of Livestock. Vol.3. Oxford University Press, Cape Town.

Worthington R.W. \& Bosman P.P. 1968. Isolation of Actinobacillus seminis in South Africa. J. South Africa Vet. Assoc. 39:81-85. 